\title{
METODE SUPPORT VECTOR MACHINE DAN FORWARD SELECTION PREDIKSI PEMBAYARAN PEMBELIAN BAHAN BAKU KOPRA
}

\author{
Ivo Colanus Rally Drajana \\ ivocolanusrally@gmail.com \\ Universitas Ichsan Gorontalo
}

\begin{abstract}
Abstrak
Telah banyak peneliti-peneliti termotivasi dalam meningkatkan kinerja performa prediksi. Support Vector Machine (SVM) metode yang berlandaskan pada teori pembelajaran statistic dan memberi hasil yang menjanjikan akan lebih baik dibanding metode lain. SVM bekerja juga dengan baik terhadap data yang berdimensi tinggi dengan menggunakan teknik kernel. Penentuan variabel yang relevan sangat dibutuhkan untuk dapat memberikan kinerja performa lebih efektif lagi pada suatu model. Pada penelitian ini bermaksud untuk mengembangkan model prediksi dengan mengkombinasikan algoritma Support Vector Machine dengan Feature Selection, khususnya forward selection dalam memprediksi pembayaran pembelian bahan baku kopra. Model yang diusulkan dievaluasi menggunakan data time pembelian bahan baku kopra. Hasil eksperimen penelitian ini menunjukan dimana series pembayaran algoritma SVM dan Forward Selection memberikan kinerja performa yang terbaik dibandingkan SVM, SVM dan Backward Elimination serta BPNN dan Feature Selection.
\end{abstract}

Kata Kunci: Support Vector Machine (SVM), Forward Selection (FS), Time Series, Prediksi

\section{Pendahuluan}

Pembayaran adalah cara yang berhubungan dengan pemindahan sejumlah nilai uang dari salah satu pihak ke pihak lainya. Pembayaran adalah salah satu bentuk transaksi keuangan. Transaksi eksternal transaksi yang terjadi diantara perusahaan dengan pihak luar sedangkan transaksi yang internal transaksi hanya terjadi didalam unit perusahaan[1]. Kegiatan pembelian bahan baku adalah salah satu hal terpenting didalam suatu proses perbisnisan. Kopra adalah salah satu jenis bahan baku yang siap olah. Bahan baku kopra dapat diperoleh secara langsung dari sumber alam. Hasil olahan komoditi kelapa beruba kopra merupakan bahan baku bagi perusahaan minyak kelapa dalam Crude Coconut Oil yang kemudian diproses menjadi produk lebih berkualitas seperti minyak yang telah melewati tahap proses Refinery, Bleaching, dan Deodorize (RBD) [2]. Pembayaran pembelian bahan baku kopra tiap harinya atau minggunya mengalami perubahan fluktuatif. Dalam melakukan peramalan metode yang umum digunakan adalah metode time series, nilai dimasa yang akan datang dapat diketahui berdasarkan urutan waktu pengamatannya. Metode time series memiliki kemampuan yang tinggi dengan cara melihat nilai dari masa lalu[3].

Algoritma Support vector machine (SVM) memiliki kelebihan dalam menunjukan performa yang sangat baik untuk prediksi time series[4]. Algoritma SVM adalah metode yang berlandaskan pada teori pembelajaran statistic dan memberi hasil yang menjanjikan akan lebih baik dibanding metode lain. SVM bekerja juga dengan baik terhadap data yang berdimensi tinggi dengan menggunakan teknik kernel[5]. Metode SVM tidak menghasilkan hasil yang akurat ketika banyak fitur yang tidak relevan, tidak semua fitur diperlukan dalam proses. Seleksi fitur bekerja secara langsung mengurangi jumlah fitur dan memilih fitur yang benar-benar memberikan informasi,jumlahfitur berkurang secara signifikandan masalahoverfitting teratasi. Metode SVM memberikan kinerja yang efektif, ketika fitur yang tidak relevan dihilangkan[6]. Algoritma forward selectiondapat mengoptimaikan variabel yang akan dimasukan kedalam model. Performa metode forward selection lebih baik dibandingkan dengan metode backward elimination serta mendapatkan model yang lebih baik dalam memprediksi[7]. Penelitian ini memiliki tujuan menerapkan model prediksi menggunakan algoritma SVM dan Forward Selection untuk meramalkan pembayaran pembelian bahan baku kopra. Peneliti juga membandingkan algoritma yang diterapkan dengan metode Backpropagation Neural Network (BPNN).

\section{Landasan Teori}

\subsection{Feature Selection}

Forward Selection salah satu prosedur berstep yang memiliki tujuan untuk menggandakan variabel yang dikendalikan satu demi satu ke dalam persamaan yang dilandaskan pada alpha tertentu buat masukan. Alpha buat masukkan merupakan nilai yang yang menjadi tolak ukur apakah salah satu 
ILKOM Jurnal IImiah Volume 9 Nomor 2 Agustus 2017

predictor yang saat ini tidak dalam model, harus ditambahkan ke model[8]. Backward Elimination adalah salah satu metode yang memiliki fungsi untuk pengoptimalan kinerja suatu model dengan carakerja system pemilihan mundur. Dalam pemilihan variabel ini dilakukan dengan cara pemilihan mundur yaitu menguji semua variabel setelah itu menghapus variabel-variabel yang dianggap tidak relevan. Variabel yang diproses, jika dianggap tidak signifikan atau berpengaruh didalam model maka akan dihapuskan dari model. Proses eliminasi ini akan dihentikan jika semua variable yang telah masuk selesai diproses[9].

\subsection{Support Vector Machine}

Support Vector Machine (SVM) kali pertama diperkenalkan oleh Vapnik tahun 1992 sebagai rangkaian harmonis konsep-konsep utama didalam bidang pattern recognition. Secara sederhana konsep SVM dapat dijelaskan sebagai usaha mencari hyperplane-hyperplane terbaik yang berfungsi sebagai pemisah dua buah class pada input space[10].

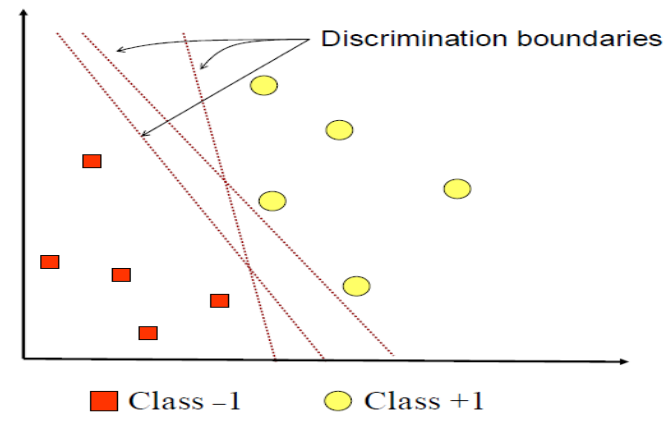

(a)

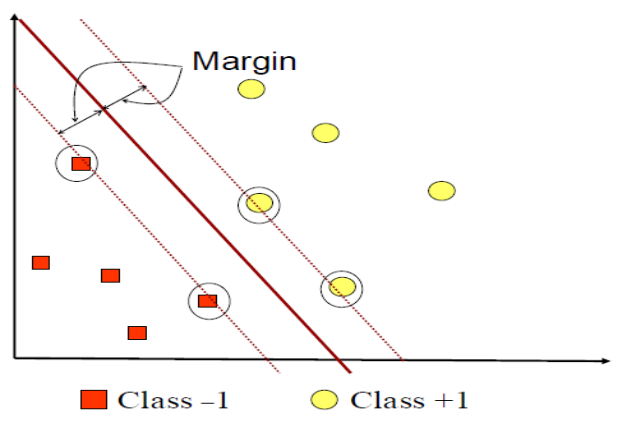

(b)

Gambar 1. SVMBerusaha Menemukan Hyperplane Terbaik

Gambar 1a memperlihatkan beberapa pattern yang merupakan anggota dari dua buah class : +1 dan -1 . Pattern yang tergabung pada class -1 disimbolkan dengan warna merah, sedangkan pattern pada class +1 , disimbolkan dengan warna kuning. Problem klasifikasi dapat diterjemahkan dengan usaha menemukan garis (hyperplane) yang memisahkan antara kedua kelompok tersebut. Berbagai alternatif garis pemisah (discrimination boundaries) ditunjukkan pada gambar 1a.Hyperplane pemisah terbaik antara kedua class dapat ditemukan dengan mengukur margin hyperplane tersebut dan mencari titik maksimalnya. Margin adalah jarak antara hyperplane tersebut dengan pattern terdekat dari masing-masing class. Pattern yang paling dekat ini disebut sebagai support vector. Garis solid pada gambar $1 \mathrm{~b}$ menunjukkan hyperplane yang terbaik, yaitu yang terletak tepat pada tengah-tengah kedua class, sedangkan titik merah dan kuning yang berada dalam lingkaran hitam adalah support vector. Usaha untuk mencari lokasi hyperplane ini merupakan inti dari proses pembelajaran pada SVM.

Proses pembelajaran SVM adalah untuk menentukan support vector, kita hanya cukup mengetahui fungsi kernel yang dipakai, dan tidak perlu mengetahui wujud dari fungsi non-linear. Persamaan SVM:

$$
f(x)=w^{t} \phi(x)+b
$$

Dimana:

$$
\begin{array}{ll}
\boldsymbol{b} & =\text { Bias } \\
\boldsymbol{x}=\left(\boldsymbol{x}_{1}, \boldsymbol{x}_{2, \ldots \ldots . . .} \boldsymbol{x}_{\boldsymbol{D}}\right)^{\boldsymbol{T}} & =\text { Variabel Input } \\
\boldsymbol{w}=\left(\boldsymbol{w}_{\mathbf{0}}, \boldsymbol{w}_{1}, \ldots \ldots . . . \boldsymbol{w}_{\boldsymbol{D}}\right)^{\boldsymbol{T}} & =\text { Parameter Bobot } \\
\phi(\boldsymbol{x}) & =\text { Fungsi Transformasi fitur }
\end{array}
$$

SVM adalah algoritma yang memiliki kelas metode kernel, yang berakar pada teori belajar statistik. Kernel berfungsi sebagai dasar pembelajaran semua algoritma, algoritma ini bertujuan umum masalah fungsi kernel tertentu. Karena mesin linear hanya dapat mengklasifikasi data dalam linear ruang fitur terpisah. Fungsi peran kernel untuk mendorong sebuah ruang fitur oleh implisit pemetaan data pelatihan kedalam ruang dimensi yang lebih tinggi dimana data adalah linear terpisah. Tujuan dari SVM adalah untuk merancang cara pembelajaran komputasi yang efisien dalam pemisahan 
ILKOM Jurnal IImiah Volume 9 Nomor 2 Agustus 2017

hyperplane didalam ruang fitur berdimensi tinggi[11]. Dalam algoritma SVM ada trik kernel dimana ada SVM linear dan SVM nonlinear. Dimana SVM adalah hyperplane linear yang bekerja hanya pada data yang hanya dapat dipisahkan dengan caralinear. SVM nonlinear yaitu data yang berdistribusi pada kelas yang tidak linear sering digunakan pendekatan kernel pada fitur awal data set. Dimana kernel dapat diartikan sebagai suatu fungsi yang memetakan fitur data yang memiliki dimensi awal rendah fitur lainya yang berdimensi lebih tinggi bahkan jauh lebih tinggi. Masalah data yang sifatnya tidak linear, kita memerlukan penggunaan fungsi kernel[12].

Fungsi kernel Polynomial

$$
K(x, y)=(x \cdot y+c)^{d}
$$

Dimana.

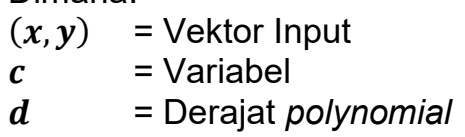

\subsection{Backpropagation Neural Network (BPNN)}

Algoritma Neural Network adalah salah satu metode yang bekerja berlandaskan cara kerja pada otak manusia. Informasi dikirimkan ke neuron melalui suatu input pembobotan. Langkah selanjutnya memproses input oleh fungsi propagation yang akan menaikkan nilai input bobot. Kemudian hasil akan dibandingkan dengan threshold oleh fungsi aktifasi, jika didapati input melewati batas threshold, maka neuron diaktifkan, namun jika tidak neuron akan di inhibit. Jika neuron diaktifkan, maka neuronakan mengirim output dengan cara melalui pembobotan output ke neuron lainnya, demekian seterusnya. Neural Network didalam data mining dipergunakan untuk proses peramalan kelas suatu data uji baru yang ditemukan[13]. Metode backpropagation merupakan salah satu metode pelatihan paling terpopuler. Backpropagation sering digunakan dalam menyelesaikan permasalahan, yang salah satunya dalah prediksi. Cara kerja pelatihan metode backpropagationsama dengan perceptron dimana sejumlah data latih sebagai pola masukan dikirimkan pada jaringan kemudian menghitung pola keluaran namun jika ditemukan error maka bobot didalam jaringan akan diperbaharui yang bertujuan untuk mengurangi error tersebut. Dimana error merupakan perbedaan anatar target keluaran yang diharapkan dengan nilai keluaran[14].

\subsection{Root Mean Square Error}

Untuk mendapatkan hasil keakuratan dari sebuah peramalan, diperlukan evaluasi terhadap data yang sebenarnya. Ada beberapa metode yang sering digunakan untuk melakukan perhitungan kesalahan peramalan salah satunya adalah root mean square error (RMSE), metode ini sering digunakan dalam mengevaluasi hasil peramalan. Ukuran yang sering digunakan dari perbedaan antara nilai-nilai diprediksi oleh model atau estimator dan nilai-nilai benar-benar diamati yaitu RMSE. Perbedaan-perbedaan individual disebut residual ketika perhitungan dilakukan atas sampel data yang digunakan untuk estimasi, dan disebut kesalahan prediksi ketika dihitung out-of-sample. RMSE memiliki fungsi untuk agregat besaran kesalahan dalam prediksi untuk berbagai kali menjadi ukuran tunggal daya prediksi. RMSE merupakan ukuran akurasi yang baik, tapi hanya untuk membandingkan kesalahan peramalan model yang berbeda untuk variabel tertentu dan tidak antara variabel, karena skala-dependent[15]. MenurutRaharja, A[16], berikut persamaan root means square error (RMSE).

Dimana:

$$
R M S E=\sqrt{\frac{\sum\left(y_{t}-\hat{y}_{t}\right)^{2}}{n}}
$$

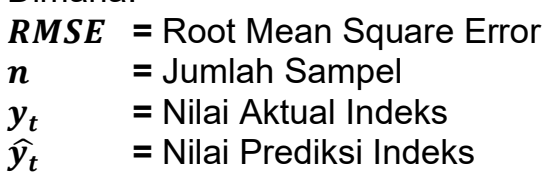

\subsection{Data Time Series}

Teknik data mining adalah bagaimana menelusuri data yang ada untuk membangun sebuah model, kemudian menggunakan model tersebut agar dapat mengenali pola data yang lain yang tidak berada dalam basis data yang tersimpan. Kebutuhan untuk prediksi juga data memanfaatkan teknik ini. Dalam data mining pengelompokkan data juga bias dilakukan. Tujuannya adalah agar kita dapat 
ILKOM Jurnal IImiah Volume 9 Nomor 2 Agustus 2017

mengetahui pola universal data-data yang ada. Semual hal tersebut bertujuan mendukung kegiatan operasional perusahaan sehingga tujuan akhir perusahaan diharapkan dapat tercapai[17]. Dalam perkembangan analisis data time series, banyak fenomena yang menarik dan sederhana merupakan fenomena yang non-linear (hubungan antara kejadian di masa lalu dan saat ini adalah non-linear). Sehingga pemodelan data time series yang linear tidaklah cukup dan sesuai untuk menangani kasuskasus tersebut. Sebagai konsekuensinya, model-model time series nonlinear telah menjadi perhatian utama para peneliti prediksi time series pada beberapa tahun terakhir ini. Beberapa bentuk model non-linear telah dikembangkan dan diaplikasikan pada beberapa kasus time series, dan sebagai overview[18].

\section{Metode}

Pada penelitian ini sumber data di ambil dari data set PT. Multi Nabati Sulawesi Unit Maleo Kabupaten Pohuwato. Data yang dikumpulkan adalah data harian time series univariat. Jenis data berupa data pembayaran pembelian bahan baku kopra data yang diperoleh mulai dari tahun 20082014. Data set yang ada khusus untuk hari minggu tidak terjadi transaksi serta hari libur kalender setiap tahunya. Data set dari variabel pembayaran memiliki 362 record yang berasal dari setiap relasi perusahaan.Dalam desain dan perancangan juga harus mengetahui pola data yang ada, data set termasuk dalam data set linear atau data set nonlinear. Pola data set pembayaran pembelian bahan baku kopra dapat dilihat pada sampel data pembayaran dibawah ini:

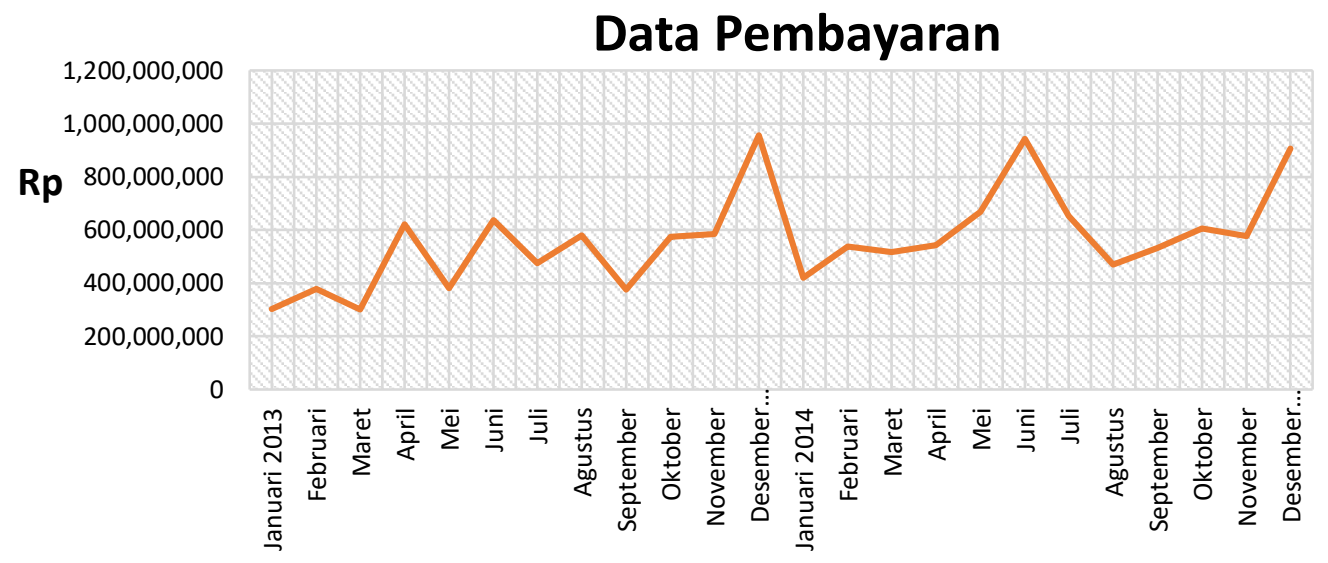

Gambar2.Grafik Pembayaran Kopra Tahun 2013-2014

Sesuai dengan gambar 2 data set pembayaran kopra, grafik tersebut menjelaskan bahwa data set tersebut termasuk dalam data set nonlinear. Data yang menghasilkan kelas tidak linear sering memanfaatkan pendekatan kernel.

Tahap preprocessing tahap pengolahan data univariat time series berupa numerik data harian. Data disusun menjadi data mingguan, agar lebih mudah proses pengolahannya, data di ubah dari data ascending menjadi descending proses ini dilakukan denga cara memanfaatkan toolbar sort \& filter yang ada pada excel. Kemudian data akan dinormalisai. Pada ilmu database atau basis data, normalisasi berfungsi untuk menghindari terjadinya berbagai anomaly data dan tidak konsistensinya data. Normalisasi database bertujuan untuk memperoleh data yang memiliki ukuran lebih kecil untuk mewakili data asli dengan tidak kehilangan karakteristis dirinya[19]. Dengan persamaan sebagai berikut:

$$
\text { Normalisasi }=\frac{(X-\min )}{(\max -\min )}
$$

Dimana:

$$
\begin{array}{ll}
\boldsymbol{x} & =\text { Data } \\
\operatorname{Min} & =\text { Data Minimum } \\
\operatorname{Max} & =\text { Data Maksimum }
\end{array}
$$


ILKOM Jurnal IImiah Volume 9 Nomor 2 Agustus 2017

Denormalisasi dataset adalah mengembalikan ukuran dataset yang sudah ternormalisasi untuk mengembalikan data asli. Denormalisasi diterapkan pada hasil eksperimen data testing yang berupa prediksi pembayaran pembelian bahan baku kopra. Persamaan dapat dilihat sebagai berikut:

$$
\text { Denormalisasi }=Y(\max -\min )+\min
$$

Dimana:

$$
\begin{array}{ll}
\boldsymbol{Y} & =\text { Hasil Keluaran Dari Pelatihan } \\
\text { Min } & =\text { Data Minimum } \\
\text { Max } & =\text { Data Maksimum }
\end{array}
$$

Dari hasil data normalisasi, data diubah univariat menjadi multivariate, kemudian data di ubah dari 1 sampai 7 periode. demikian halnya data training diubah menjadi multivariable independent, baik itu 1 periode sampai 7 periode memiliki masing-masing 1 variabel dependent. Sebagai sampel data 1 periode $(x t-1: x t)$, data 2 periode $(x t-2, x t-1: x t)$, serta dengan data 7 periode $(x t-7, x t-6, x t-5, x t-4, x t-$ 3, $x t-2, x t-1: x t)$ demikian juga pada data testing. Proses ini dilakukan secara manual di excel. Pengubahan data jadi beberapa periode guna untuk mendapatkan model yang tepat buat memprediksi pembayaran pembelian bahan baku kopra.

Time series multivariat memodelkan peubah-peubah yang berkorelasi dan tercatat dari waktu kewaktu. Peubah tersebut dapat dinotasikan dalam tabel dibawah ini:

Tabel 1.Pola data Time Series Univariat ke Multivariate

\begin{tabular}{|c|l|c|}
\hline Pettren & \multicolumn{1}{|c|}{ Input Lag } & Output \\
\hline 1 & $x 1, x 2, \ldots \ldots, x p$ & $x p+1$ \\
\hline 2 & $x 2, x 3, \ldots \ldots, x p+1$ & $x p+1$ \\
\hline 3 & $x 3, x 4, \ldots \ldots, x p+2$ & $x p+1$ \\
\hline$\ldots$ & $\ldots \ldots \ldots \ldots$ & \\
\hline$m-p$ & $x m-p, x m-p+1, x m-p+2, x m-p+3 \ldots, x m-1$ & $x m$ \\
\hline
\end{tabular}

Sesuai tabel 1 merupakan pola yang digunakan dalam mengubah data univariat ke multivariat, pola dan modelnya dapat dilihat seperti :

model $: x m-p, x m-p+1, x m-p+2, x m-p+3 \ldots, x m-1$

Dimana:

$\begin{array}{ll}\boldsymbol{m}-\boldsymbol{p} & =\text { Nilai Pettren } \\ \boldsymbol{x} \boldsymbol{m}-\boldsymbol{p} & =\text { Input Lag } \\ \boldsymbol{x} \boldsymbol{m} & =\text { Output/Target }\end{array}$

Pemodelan dari data time series multivariat bertujuan untuk menentukan fungsi atau model yang tepat, dimana fungsi dari model tersebut dapat digunakan untuk memprediksi nilai-nilai yang akan datang dengan baik buat semua peubah didalam sistem. Hal ini dilakukan sebagai bahan perbandingan data mana yang dianggap baik digunakan untuk prediksi. Dimana setiap variabel input yang digunakan memiliki pola yang berbeda yaitu proses pembelajaran akan performa mempunyai jumlah masukan. Tujuan proses belajar yaitu untuk mempelajari pola data time series dan mendapatkan nilai parameter yang akan digunakan untuk prediksi data time series. Dalam proses pembelajaran time series multivariate data dibagi dua yaitu data masukan (Independen) dan data target (Dependen)[20].Variabel-variabel data akan diseleksi dengan fitur seleksi forward selection yang bertujuan untuk memilih variabel yang memberikan informasi keakuratan prediksi agar performa algoritma dapat dioptimalkan. Forward selection tujuan kerjanya membangun model simulai dengan tidak ada variabel dalam model dan menambahkan variabel yang berguna satu persatu. Proses data yang ditraning dikerjakan secara step-by-step diawali mulai dari 1 variabel sampai dengan jumlah variabel yang menghasilkan performa akurasi paling baik.

\section{Eksperimen Dan Pengujian}

Eksperimen dilakukan dengan beberapa tahapan. Pada tahap 1 preprocessing data yang bertujuan mengubah data dari harian menjadi mingguan. Tahap 2 data diubah dari ascending ke descending. Tahap 3 melakukan normalisasi data. Tahap 4 data diubah dari univariat ke multivariat. 
ILKOM Jurnal IImiah Volume 9 Nomor 2 Agustus 2017

Tahap 5 menentukan parameter SVM dan forward selection. Dalam penentuan parameter SVM dilakukan beberapa pengujian seperti penentuan jumlah variabel input independent atau variabel periode $x t-i$ dan pemilihan type kernel, percobaan ini digunakan untuk menemukan model terbaik dengan melihat tingkat nilai root mean square error yang terkecil. Setelah melewati tahapan demi tahapan sampai pada penentuan parameter SVM dan Forward Selection serta Backward Elimination membandingkan BPNN dan Forward Selection serta Backward Elimination, dilanjutkan pada tahap 6 yaitu pengaplikasian model yang terbaik yang dihasilkan algoritma SVM terhadap data testing untuk melakukan peramalan.Proses eksperimen digunakan beberapa sampel data set dalam melakukan uji coba, kemudian dilanjutkan dengan penetapan parameter sebelum memulai proses uji coba nilai parameter yang digunakan dalam proses uji coba sama dengan nilai training yaitu nilai variabel input atau variabel periode $x t-i$ dari $1-7$, number of validation 10 dengan type kernel polynomial dan $C$ (cost) kemudian dilakukan proses testing untuk mengetahui hasi root mean square error.

Tabe2. Nilai RMSE pada SVM, SVM dan Feature Selection

\begin{tabular}{|c|c|c|c|c|c|}
\hline $\begin{array}{c}\text { Nilai } \\
\text { Variabel } \\
\text { Periode }\end{array}$ & $\begin{array}{c}\text { Number } \\
\text { of } \\
\text { Validation }\end{array}$ & $\begin{array}{c}\text { Type } \\
\text { Kernel }\end{array}$ & $\begin{array}{c}\text { RMSE } \\
\text { SVM }\end{array}$ & $\begin{array}{c}\text { RMSE } \\
\text { Forward } \\
\text { Selection }\end{array}$ & $\begin{array}{c}\text { RMSE } \\
\text { Backward } \\
\text { elimination }\end{array}$ \\
\hline 1 & 10 & polynomial & 0,135 & 0,135 & 0,135 \\
\hline 2 & 10 & polynomial & $\mathbf{0 , 1 3 3}$ & 0,134 & 0,135 \\
\hline 3 & 10 & polynomial & 0,136 & 0,132 & 0,135 \\
\hline 4 & 10 & polynomial & 0,147 & 0,134 & 0,135 \\
\hline 5 & 10 & polynomial & 0,143 & 0,134 & $\mathbf{0 , 1 3 3}$ \\
\hline 6 & 10 & polynomial & 0,150 & 0,132 & $\mathbf{0 , 1 3 3}$ \\
\hline 7 & 10 & polynomial & 0,159 & $\mathbf{0 , 1 3 1}$ & $\mathbf{0 , 1 3 3}$ \\
\hline
\end{tabular}

Sesuai dengan tabel 2 adalah tabel rangkuman hasil eksperimen uji coba pembayaran kopra dengan pemilihan model menggunakan algoritma support vector machine (SVM), SVM dan Forward Selection, SVM dan Backward Elimination mulai dari 1 sampai 7 variabel periode untuk data pembayaran kopra menggunakan number of validation 10 dan type kernel polynomial yang diambil berdasarkan tingkat nilai root mean square error (RMSE) paling terkecil. Maka ditemukannya model terbaik yang dilihatkan berdasarkan tingkat nilai error terkecil algoritma SVMpada periode 2 yang bernilai 0,133 , algoritma SVM dan forward selectionpada periode 7 yang bernilai 0,131 , sedangkan algoritma SVM dan backward eliminationpada periode 5,6, dan 7 yang bernilai 0,133.

Sesuai hasil eksperimen pengolahan model forward selection menampilkan bahwa nilai pada attribute weights menampilkan nilai pada variabel $x t-1$ dan $x t-6$ adalah 1 dan nilai pada variabel $x t-2$, $x t-3, x t-4, x t-5$ dan $x t-7$ adalah 0 , dengan demikian variabel yang dianggap signifikan adalah variabel $x t-1$ dan variabel $x t-6$.Sesuai hasil eksperimen pengolahan model backward elimination periode 5 menampilkan bahwa nilai pada attribute weights menampilkan nilai pada variabel $x t-1$ dan $x t-2$ adalah 1 dan nilai pada variabel $x t-3, x t-4$ dan $x t-5$ adalah 0 , dengan demikian variabel yang dianggap signifikan adalah variabel $x t-1$ dan variabel $x t-2$, periode 6 menampilkan bahwa nilai pada attribute weights menampilkan nilai pada variabel $x t-1$ dan $x t-6$ adalah 1 dan nilai pada variabel $x t-2, x t-3, x t-4$ dan $x t-5$ adalah 0 , dengan demikian variabel yang dianggap signifikan adalah variabel $x t-1$ dan variabel $x t-6$, dan periode 7 menampilkan bahwa nilai pada attribute weights menampilkan nilai pada variabel $x t-1$ dan $x t 6$ adalah 1 dan nilai pada variabel $x t-2, x t-3, x t-4, x t-5$ dan $x t-7$ adalah 0 , dengan demikian variabel yang dianggap signifikan adalah variabel $x t-1$ dan variabel $x t-6$.

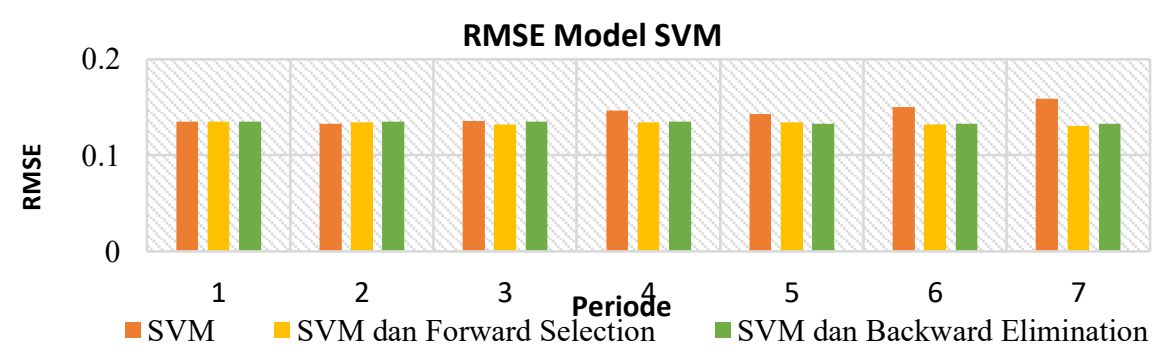

Gambar 3.Grafik RMSE Model SVM, SVM dan Feature Selection

Sesuai dengan gambar 3 yaitu grafik perbandingan model yang paling baik untuk data pembayaran kopra, algoritma SVM, SVM dan forward selection serta SVM dan backward elimination menggambarkan bahwa model terbaik algoritma SVM terdapat pada variabel periode 2, dengan number of validation 10 dan type kernel polynomial yaitu tingkat RMSE sebesar 0,133. Pada model 
ILKOM Jurnal IImiah Volume 9 Nomor 2 Agustus 2017

SVM dan forward selection terdapat pada variabel periode 7, dengan number of validation 10 dan type kernel polynomial pada forward selection yaitu tingkat RMSE sebesar 0,131 , sedangkan pada backward elimination terdapat kesamaan hasil RMSE, variabel periode 5, 6 dan 7, dengan number of validation 10 type kernel polynomial pada yaitu tingkat RMSE 0,133.

\subsection{Perbandingan Model}

Pada penelitian ini juga melakukan eksperimen menggunakan model BPNN, BPNN dan Forward Selection serta BPNN dan Backward Elimination. Dimana hasil perbandingan RMSE antar model BPNN, BPNN dan Feature Selection dapat dilihat pada gambar 3.

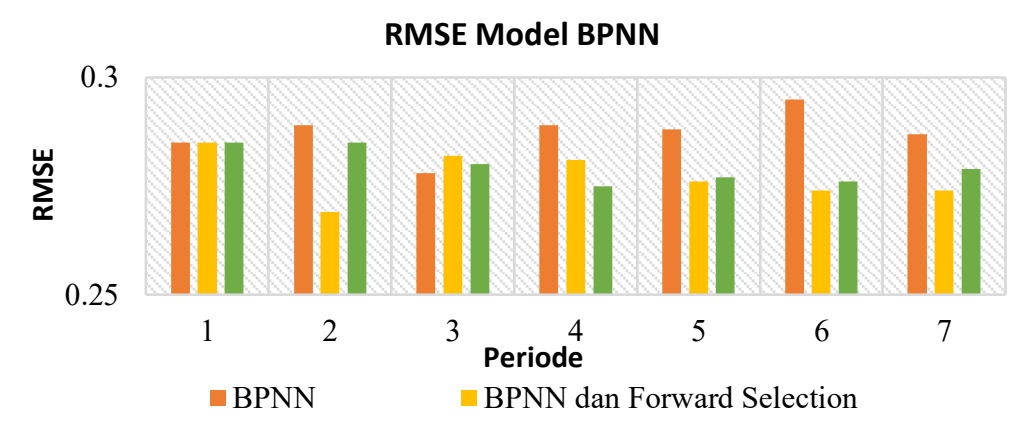

Gambar 4.Grafik RMSE Model BPNN, BPNN dan Feature Selection

Sesuai dengan gambar 4 yaitu merupakan grafik perbandingan model BPNN, BPNN dan Forward Selection serta BPNN dan Bacward Elimination menggambarkan bahwa model terbaik pada variabel periode 2 dengan feature selection menggunakan Forward Selection dengan tingkat nilai RMSE 0,269.

Hasil dari perbandingan prediksi RMSE menggunakan algoritma SVM dan Feature Selection dan BPNN dan Featute Selection dapat dilihat pada table berikut:

Tabel3. Nilai RMSE pada SVM dan Feature Selection, BPNN dan Feature Selection

\begin{tabular}{|l|c|c|}
\hline \multicolumn{1}{|c|}{ Algoritma } & Nilai Variabel Periode & RMSE \\
\hline SVM & 2 & 0,133 \\
\hline \multirow{3}{*}{ SVM Forward Selection } & $\mathbf{7}$ & $\mathbf{0 , 1 3 1}$ \\
\hline \multirow{3}{*}{ BPNN } & 5 & 0,133 \\
\cline { 2 - 3 } & 6 & 0,133 \\
\cline { 2 - 3 } & 7 & 0,133 \\
\hline BPNN Forward Elimination Selection & 3 & 0,278 \\
\hline BPNN Bacward Elimination & 2 & 0,269 \\
\hline
\end{tabular}

Sesuai dengan tabel3 menunjukan bahwa model yang tepat digunakan untuk melakukan peramalan pembayaran pembelian bahan baku kopra yaitu pada model algoritma SVM dan Forward Selection dikarenakan tingkat nilai RMSE terkecil.

\section{Kesimpulan}

Sesuai hasil eksperimen yang telah dilakukan untuk prediksi pembayaran pembelian bahan baku kopra dengan menerapkan algoritma Support Vector Machine (SVM) dan Forward Selection telah berhasil dilakukan. Dari hasil eksperimen yang dilakukan menjelaskan bahwa feature selection yaitu forward selection adalah model yang terbaik dalam menyeleksi variabel yang signifikan jika dibandingkan dengan backward elimination. Algoritma Support Vector Machine dan Forward Selection telah memberikan performa kinerja yang lebih baik dibandingkan dengan algoritma SVM, SVM dan Backward Elimination dan BPNN.

\section{Daftar Pustaka}

[1]. Nurwarsito, H. Desember 2009. Sistem Transaksi Pembayaran Food Court Dengan Teknologi E-Card, Jurnal EECCIS Vol. III, No. 2.

[2] Pakasi, Caroline, B.D. Juni 2013. Pengembangan Kelapa Sebagai Komoditi Unggulan Daerah Sulawesi Utara dengan Pendekatan Klaster Industri, Seminar Nasional : Menggagas 
Kebangkitan Komoditas unggulan Lokal Pertanian dan Kelautan Fakultas Pertanian Universitas Trunojoyo Madura, Universitas Sam Ratulangi Manado.

[3]. Sularno, A. 2014. Prediksi Nilai Saham Menggunakan Pemograman Genetika Dan Pemograman Ekspresi Gen, Universitas Gunadarma Depok. Indonesia.

[4]. Widodo, A, Budi, I, dan Aji, R.F. 2012. Prediksi topic penelitian menggunakan kombinasi antar Supprot Vector Regression dan Kurva Logistik, Universitas Indonesia, Seminar Nasioanal Aplikasi Teknologi Informasi, ISSN:1907-5022, Yogyakarta.

[5]. Prasetyo, Eko. 2012.Data mining Konsep dan Aplikasi menggunakan Matlab, ANDI, Yogyakarta, 177.

[6]. Y Liu, YF Zheng. 2012. FS_SFS:Anovel feature selection method for support vector machines, The Ohio State University, Columbus OH 43210, USA. Pattern recognition.

[7]. Neneng, S. 2009. Seleksi Variabel dalam Analisis Regresi Multivariat Multiple, Stap Jurusan Statistika FMIPA UNPAD, Seminar Nasional dan Pendidikan Matematiaka, ISBN: 978-97916353-3-2.

[8]. F.G, Blanchet, P, Legendre, and D. Borcard. 2008. Forward Selection Of Explanatory Variables. Ecology, Vol. 89. No. 9, - Eco Soc America.

[9]. Intan Martina Md Ghani dan Sabri Ahmad. 2011.Comparison Methods of Multiple Linear Regression in Fish Landing, Australian Journal of Basic and Applied Sciences, 5(1): 25-30.

[10]. Nugroho, A.S, Witarto, A.B, Handoko, D. 2003. Supprot Vector Machine Teori dan Aplikasinya dalam Bioinformatika.

[11]. M, Hofmann. 2007. Support Vector Machines - Kernels and the Kernel Trick.

[12]. Prasetyo Eko. 2012. Data Mining Konsep dan Aplikasi menggunakan Matlab, ANDI, Yogyakarta, 127-130.

[13]. Prasetyo Eko. 2012. Data Mining Konsep dan Aplikasi Menggunakan Matlab, ANDI, Yogyakarta, 72-73.

[14]. Raharjo, J.S.D. Juni 2013. Model Artificial Neural Network Berbasis Particle Swarm Optimization untuk Prediksi Laju Inflasi, Sekolah Tinggi Manajemen Informatika dan Komputer Eresha Jakarta, Jurnal Sistem Komputer, Vol. 3, No. 1, ISSN: 2087-4685.

[15]. Fikri, A. 2013. Penerapan Data Mining Untuk Mengetahui Tingkat Kekuatan Beton Yang Dihasilkan Dengan Metode Estimasi Menggunakan Linear Regression, Universitas Dian Nuswantoro Semarang.

[16]. Alda Raharja dan Wiwik Anggraeni, S.Si, M.Kom dan Retno Aulia Vinarti, S.Kom. 2010. Menerapkan Metode exponential Smooting untuk Peramalan penggunaan waktu telpon di Pt.telkomsel divre3,SISFO-Jurnal Sistem Informasi.

[17]. Prasetyo Eko.2012.Data Mining Konsep dan Aplikasi menggunakan matlab, ANDI Yogyakarta, 2.

[18]. Suhartono. 2007.Feedforward Neural Networks Untuk Pemodelan Runtun Waktu, Universitas Gadjah Mada Yogyakarta, 25 September.

[19]. Indrabayu, Harun, N dan Pallu, M.S, Achmad, A, dan L, F,I. 2012. Prediksi Curah Hujan dengan Jaringan Saraf Tiruan, Universitas Hasanuddin, ISBN: 978-979-127255-0-6, Vol. 6, Makassar Desember.

[20]. Purwanto, C. Eswaran dan Logeswaran, R. 2011, Improved Adaptive Neuro-Fazzy Inference System for HIVIAIDS time series Prediction, A. Abd Manaf et al. (Eds): ICIEIS 2011, Part III, CCIS 253, pp. 1-13. 